\title{
HUBUNGAN MINAT BELAJAR TERHADAP HASIL BELAJAR SISWA PADA MATA PELAJARAN MENGGUNAKAN PERKAKAS TANGAN KEAHLIAN TEKNIK PEMESINAN DI SMK NEGERI 2 BANDA ACEH \\ THE RELATIONSHIP BETWEEN STUDENTS LEARNING INTEREST AND STUDENTS \\ LEARNING OUTCOMES ON USING HAND TOOLS IN MECHANICAL ENGINERING SUBJECT AT THE SMK 1 BANDA ACEH
}

\author{
Supardi ${ }^{(1)}$, Arwizet ${ }^{(1)}$. \\ Jurusan Teknik Mesin, Fakultas Teknik, Universitas Negeri Padang \\ Kampus Air Tawar, Padang 25131, Indonesia \\ Supardi@gmail.com
}

\begin{abstract}
Abstrak
Penelitian ini bertujuan untuk mengetahui hubungan minat dengan hasil belajar pada mata pelajaran perkakas tangan di SMKN 2 Banda Aceh. Penelitian ini tergolong penelitian korelasional. Populasi dalam penelitian berjumlah 97 orang siswa, dengan total sampel berjumlah 50 orang siswa. Hasil uji reliabilitas sebesar 0.931 berkategori reliabel/handal. Minat belajar berada pada kategori sedang dengan skor rata-rata 81,28 sedangkan skor tengah di peroleh sebesar 80. Hasil penelitian menunjukkan bahwa terdapat hubungan signifikan antara minat belajar dengan hasil belajar mata pelajaran menggunakan perkakas tangan siswa kelas X Keahlian Teknik Pemesinan di SMK Negeri 2 Banda Aceh Tahun Ajaran 2018/2019.

Kata Kunci : Hubungan, Minat Belajar, Hasil Belajar, Siswa, Perkakas Tangan.
\end{abstract}

\begin{abstract}
The research aims to find out the relationship between learning interest and students learning outcome in using hands tool in mechanical engineering at smk 1 banda aceh academic year 2018/2019. This type of research is correlational. The population is all of the students in class X at SMK 1 Banda Aceh amounted to 97 students. Samples were taken from the total population of each class using the Slovin formula so that a sample of 50 was obtained. The result of realibility test obtained $r_{11}$ amounting 0.931, so that can concluded the research instrument use reliable. Students learning interest in the moderate category. This can be seen through a description of questionnaire data that distributed to 50 respondent, where the average is 81,28 while the median is 80 . The research result show that any significant relationship between students learning interest and students learning outcome in using hand tools engineering subject at SMK 1 Banda Aceh academic year 2018/2019.
\end{abstract}

Keywords: Relationship, Interest to Learn, Learning Outcomes, Students, Hand Tools. 


\section{Pendahuluan}

Pendidikan adalah proses pengembangan dan peningkatan taraf SDM. Pendidikan diharapkan menimbulkan perubahan pada diri seseorang seperti aspek kognitif, efektif dan psikomotor (Jasman : 2018). Sekolah merupakan lembaga pendidikan tempat proses belajar mengajar berlangsung. Dengan proses inilah tujuan pendidikan akan tercapai dalam bentuk perubahan tingkah laku siswa (Ambiyar : 2016). Sekolah Menenga Kejuruan (SMK) adalah Pendidikan formal yang mendidik sumber daya manusia terampil dan siap masuk dunia kerja (Waskito : 2016).

Faktor yang berpengaruh terhadap minat belajar ada dua yaitu internal dan eksternal (Suparno :2017). Dalam belajar diperlukan pemusatan untuk membangkitkan minat belajar siswa (Syaiful Djamarah 2002:158). Salah satu program pengajaran jenjang pendidikan SMK yaitu Menggunakan Perkakas Tangan (MPT). MPT memfokuskan kajiannya kepada alat-alat perkakas tangan dan proses pengembangan kemampuan menggunakan peralatan perkakas tangan.

Pembelajaran merupakan interaksi antara guru dengan siswa. Pembelajaran yang baik bisa menumbuhkan minat belajar agar terjadi perubahan tingkah laku.

\section{Metode Penelitian}

Penelitian ini tergolong jenis penelitian korelasional. Penelitian korelasional adalah jenis penelitian bertujuan untuk mengetahui besarnya kontribusi antar variabel-variabel (Suharsimi Arikunto, 2002:291). Hal ini sesuai dengan pengemukaan Sumadi Suryabrata (2010:82) " bahwa penelitian yang bersifat korelasional bermaksud untuk mendeteksi sejauh mana variasi-variasi pada satu atau lebih faktor lain berdasarkan pada keofisien korelasi".

Penelitian ini bertujuan mengetahui Hubungan Minat Belajar Terhadap Hasil Belajar Siswa Pada Mata Diklat Menggunakan Perkakas Tangan Keahlian Teknik Pemesinan Di SMKNegeri 2 Banda Aceh.

\section{A. Populasi}

Populasi adalah keseluruhan objek penelitian berupa karakteristik nilai, jumlah maupun jenis dari objek (Sugiyono, 2009:117). Populasi dalam penelitian ini sebanyak 97 siswa, seperti berikut:

Tabel 1. Jumlah Siswa Kelas X Jurusan Teknik Mesin

\begin{tabular}{|c|c|c|}
\hline No & Kelas & Jumlah Siswa \\
\hline 1 & TP A & 32 siswa \\
\hline 2 & TPB & 32 siswa \\
\hline 3 & TPC & 32 siswa \\
\hline \multicolumn{2}{|c|}{ Jumlah } & 97 siswa \\
\hline
\end{tabular}

Sumber: Guru mata Pelajaran Menggunakan Perkakas Tangan SMK Negeri 2 Banda Aceh

\section{B. Sampel Penelitian}

Sampel adalah sejumlah bagian dari jumlah populasi .(Sugiyono,2009:118). Dari seluruh populasi 97 orang siswa maka teknik pengambilan sampel menggunkan rumus berikut:

$$
n=\frac{N}{N \cdot d^{2}+1}
$$

(Riduwan, 2007:65)

Pengambilan sampel sebanyak 50 orang responden, terlihat dari tabel 2 .

Tabel 2. Sampel Penelitian Kelas X Jurusan

\begin{tabular}{|c|c|c|}
\hline No & Kelas & Jumlah Siswa \\
\hline 1 & TP A & 17 siswa \\
\hline 2 & TPB & 17 siswa \\
\hline 3 & TPC & 16 siswa \\
\hline \multicolumn{2}{|c|}{ Jumlah } & 50 siswa \\
\hline
\end{tabular}

Teknik pengambailan sampel diambil secara acak dari populasi (Sugiyono, 2009:120).

\section{Uji Coba Instrumen}

Instrumen penelitian ini adalah angket atau kuesioner. Instrumen ialah alat yang dipakai sebagai pengumpulan data agar kegiatan menjadi mudah (Bulkia Rahim: 2018). 
Tabel 3. Kisi instrumen

\begin{tabular}{|c|c|c|c|c|}
\hline No & Variabel & Indikator & Item & Jumlah \\
\hline 1 & $\begin{array}{l}\text { Minat } \\
\text { belajar }\end{array}$ & $\begin{array}{l}\text { 1. Perasaan } \\
\text { senang } \\
\text { 2. Perhatia } \\
\mathrm{n} \text { dalam } \\
\text { belajar } \\
\\
\text { 3. Ketertari } \\
\text { kan } \\
\text { dalam } \\
\text { belajar } \\
\text { 4. Kepuasa } \\
\mathrm{n} \text { dalam } \\
\text { belajar }\end{array}$ & $\begin{array}{l}1,2,3,4,5,6, \\
7,8,9,10,12, \\
13,14, \\
15,16,17,18 \\
, 19,20,21,2 \\
2,23,24,25, \\
26,27,28, \\
29,30,31,32 \\
, 33,34,35,3 \\
6,37,38,39, \\
40,41,42, \\
43,44,45,46 \\
47,48,49,5 \\
0,51,52,53, \\
54,55,\end{array}$ & $\begin{array}{l}14 \\
14 \\
14 \\
13\end{array}$ \\
\hline 2 & \begin{tabular}{|l|} 
Hasil \\
belajar \\
mata \\
diklat \\
mengguna \\
kan \\
perkakas \\
tangan \\
kelas X \\
jurusan \\
teknik \\
mesin di \\
SMK \\
Negeri \\
2Banda \\
Aceh
\end{tabular} & $\begin{array}{l}\text { Di ambil } \\
\text { dari nilai } \\
\text { semester } \\
\text { ganjil } \\
\text { tahun ajara } \\
\text { 2018-2019 }\end{array}$ & & \\
\hline \multicolumn{4}{|c|}{ Jumlah } & 55 \\
\hline
\end{tabular}

Instrumen terlebih dulu diuji cobakan pada kelas lain yang sudah mempelajari perkakas tangan sebelumnya. Dengan respondennya 30 orang siswa yang tidak termasuk dalam sampel.

\section{Uji Validitas}

Uji validitas dilakukan untuk mengkorelasi skor tiap butir dengan skor total yang merupakan jumlah tiap skor butir. Uji validitas mengunakan rumus :

$$
r_{x y}=\frac{N \Sigma X Y-(\Sigma X)(\Sigma Y)}{\sqrt{\left\{N\left(\Sigma X^{2}\right)-(\Sigma X)^{2}\right\}\left\{N\left(\Sigma Y^{2}\right)-(\Sigma Y)^{2}\right\}}}
$$

(Riduwan, 2014: 80).

Pengambilan keputusan dinyatakan valid (Suharsimi Arikunto :2010) jika :

1. $r$ hitung $>r$ tabel maka item valid.

2. $r$ hitung $<r$ tabel maka item tidak valid.

Hasil analisis validitas didapat 36 item yang valid dan 4 item yang tidak valid.

\section{Uji Reabilitas}

Untuk menguji reliabilitas fasilitas belajar digunakan rumus :

$$
r 11=\left(\frac{k}{k-1}\right)\left(1-\frac{\sum \sigma_{b}^{2}}{\sigma_{t}^{2}}\right)
$$

\section{Teknik Analisis Data}

Analisis data memakai teknik analisis deskriptif. Untuk identifikasi hubungan antara minat belajar dengan hasil digunakan rumus Mean Ideal (Mi) dan standar DeviasiIdeal (SDi) Suharsimi (2002:40).

\section{Uji Normalitas}

Uji ini dilakukan untuk menguji data apakah sudah memenuhi syarat untuk dianalisis. Prayitno (2008) mengatakan "Uji normalitas menggunakan uji one sample Kolmogrov Smirnov dan taraf signifikansi 0,05 atau $5 \%$. Analisis ini menggunakan program SPSS (Statistic Product for Social Science) versi 16.0.

\section{Uji Linearitas}

Uji ini mencari persamaan garis variable bebas (X) terhadap variabel terkait (Y), dengan program SPSS.

\section{Uji Hipotesis}

a. Uji Korelasi

Uji Kolerasi menggunakan rumus korelasi product moment.

$$
r_{x y}=\frac{N \sum X Y-\sum X \sum Y}{\sqrt{\left\{N \sum X^{2}-\left(\sum X\right)^{2}\right\}\left\{N \sum Y^{2}-\left(\sum Y\right)^{2}\right\}}}
$$

Suharsimi Arikunto ( 2010:213 )

Untuk mengetahui pengaruh antara guru dengan siswa dilakukan uji signifikan dengan rumus: 
$t_{\text {hitung }}=\frac{r \sqrt{n-2}}{\sqrt{1-r^{2}}}$

Riduwan (2006:81)

b. Uji Koefisien Determinan/Kontribusi

Uji ini dengan menggunakan rumus:

$\mathrm{KD}=\mathrm{r}^{2} \times 100 \%$

\section{Hasil dan Pembahasan}

\section{A. Deskripsi Data}

Data penelitian ini minat belajar (X) dan hasil belajar siswa (Y). Deskripsi data mengungkapkan informasi tentang mean, median, mode, deviasi, keragaman, rentangan, skor min, skor max dengan program SPSS versi 20.00 .

\section{Minat Belajar $(\mathbf{X})$}

Data minat belajar (X) dikumpulkan melalui angket yang terdiri dari 40 pernyataan. Responden berjumlah 50 orang, skor terendah 100 dan tertinggi 190. Dari distribusi skor didapat mean sebesar 133.4, median 129, mode 100 dan deviasi 22.07 .

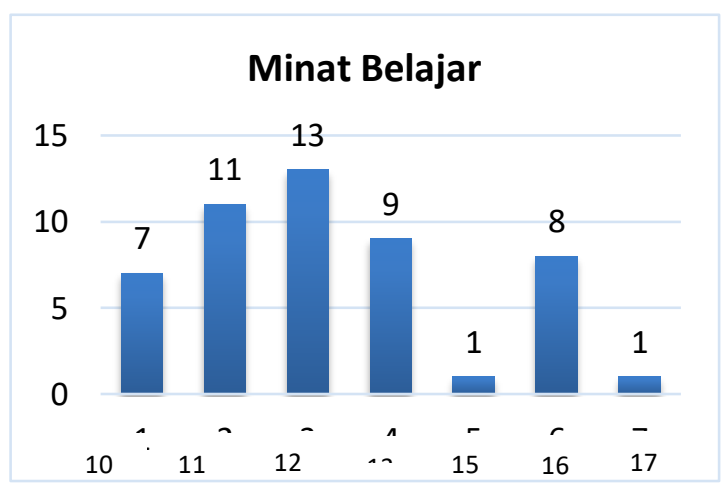

Gambar 1.Grafik Minat Belajar

Data hasil penelitian minat belajar terdapat 7 orang (14\%) minat sangat rendah, 11 orang (22\%) minat rendah, 22 orang $(44 \%)$ minat sedang, 9 orang (18\%) minat tinggi, 1 orang (2\%) minat sangat tinggi.

\section{Hasil Belajar Gambar (Y)}

Data hasil belajar diambil dari nilai rapor kelas $\mathrm{X}$ mata pelajaran menggunakan perkakas tangan. Dari data diketahui distribusi hasil belajar siswa menyebar dari skor terendah 60 dan tertinggi 95. Distribusi hasil belajar tersebut didapat mean sebesar 81,28, median sebesar 80, mode 80 dan deviasi 8,36 .

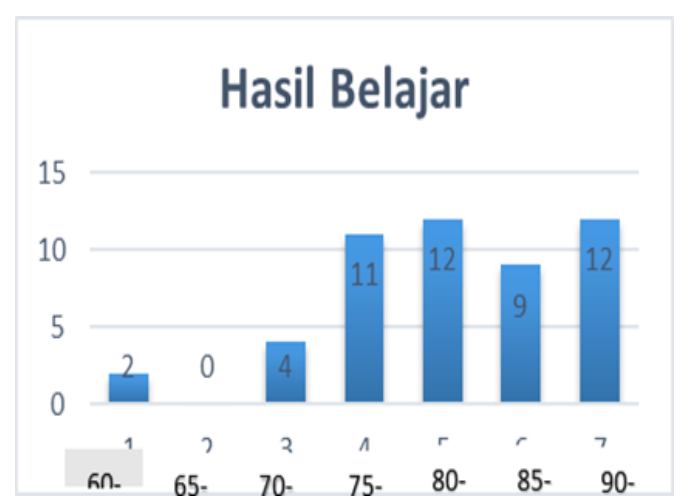

Gambar 2. Grafik Hasil Belajar Siswa

Data hasil penelitian hasil belajar terdapat 2 orang $(4 \%)$ sangat rendah, 4 orang $(8 \%)$ rendah, 11 orang $(22 \%)$ sedang, 12 orang (24\%) tinggi, 21 orang (42\%) sangat tinggi.

Dari hasil analisis diperoleh nilai signifikasi sebesar 0,99 karena signifikasi lebih dari 0,05 disimpulkan bahwa Minat Belajar (X) dengan Hasil Belajar (Y) terdapat relasi yang linear.

\section{Kesimpulan}

Hasil penelitian dapat disimpulkan sebagai berikut :

1. Minat belajar siswa menggunakan perkakas tangan keahlian kelas $\mathrm{X}$ teknik permesinan SMKN 2 Banda Aceh berkategori cukup.

2. Hasil belajar siswa kelas $X$ keahlian teknik pemesinan di SMK Negeri 2 Banda Aceh berkategori cukup.

3. Adanya relasi signifikan antara minat belajar dengan hasil belajar menggunakan perkakas tangan dengan nilai korelasi 0.467 dan nilai koefisen determinan sebesar $21,8 \%$. 


\section{Referensi}

Ambiyar dkk. (2016). Penerapan Model Pembelajaran Praktek Terbimbing Mata Diklat Las Busur Manual Untuk Meningkatkan Aktivitas dan Hasil Belajar Praktek Siswa Kelas XI Jurusan Teknik Mesin SMK Muhammadiyah 1 Padang.

Bulkia Rahim dkk. (2018). Validitas Modul Pembelajaran Model Kooperatif Tipe Jigsaw Pada Mata Kuliah Teori Teknik Fabrikasi Vol 1, No. 2.

Jasman dkk .(2018). Persepsi Siswa Terhadap Keterampilan Dasar Mengajar Mahasiswa Program Pengalaman Lapangan Kependidikan (PPLK) pada Mata Diklat Gambar Teknik di Smk Negeri 5 Padang

Nasution. S. 1982. Berbagai Proses dalam Belajar Mengajar. Bandung: Bima Aksara.

Prayitno. (2008). Uji Asumsi Normalitsas dalam SPSS

Riduwan. (2004). Belajar Mudah Penelitian

Untuk Guru-Karyawan dan Pemula.
Bandung: Albafeta.

SumadiSuryabrata. 2010. Metodologi Penelitian. Jakarta: PT Raja Grafindo Persada.

Suparno.(2017). Respon Mahasiswa Pembelajaran Kooperatif Jigsaw dan Modul Pembelajaran pada Mata Kuliah Media Pendidikan.

Syaiful Djamarah(2002) Psikologi Belajar. Rinika Cipta. 2002

Syaiful Sagala. 2006. Administrasi Pendidikan Kontemporer. Bandung:CV Alvabeta.

Slameto. 1995. Belajar dan faktor - Faktor yang mempengaruhinya. Jakarta. Rineka Cipta.

Sugiyono. 2003. Metode Penelitian Administarsi. Bandung: Alfabet

Suharsimi Arikunto. 1996. Metode Statistik. Bandung.

Waskito dkk. (2016). Kontribusi Minat Kerja dan Penguasaan Mata Pelajaran Produktif Terhadap Keberhasilan Praktek Kerja Industri Siswa Kelas XII Program Teknik Pemesinan di SMK Negeri 2 Solok. 